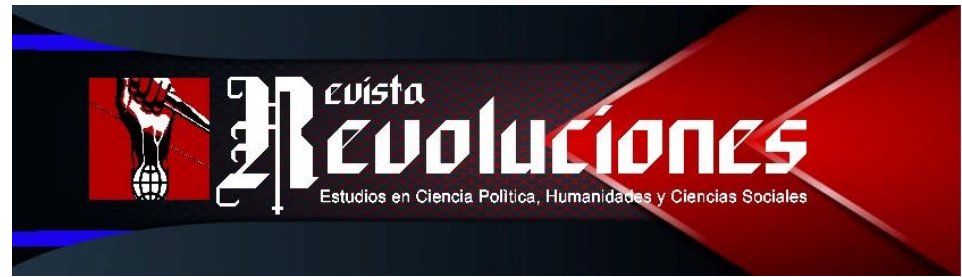

\title{
ENSAYO
}

\section{DE LA ARISTOCRACIA A LA MESOCRACIA. LOS DUEÑOS DE LA HACIENDA MARANGA, 1821-1952}

\author{
From aristocracy to mesocracy. The owners of the Maranga \\ hacienda, 1821-1952 \\ Héctor Palza-Becerra ${ }^{1}$ \\ UNIVERSIDAD NACIONAL MAYOR DE SAN MARCOS \\ PERÚ \\ hpalzab@gmail.com \\ https://orcid.org/o000-0002-2104-7305 \\ DOI: https://doi.org/10.35622/j.rr.2022.07.004 \\ Recibido: 10-XI-2021 / Aceptado: 10-II-2022 / Actualizado: 10-II-2022
}

\section{Resumen}

La presente investigación tiene por interés dar a conocer los detalles históricos del cambio de propietarios de la hacienda Maranga, entre los inicios de la república en el siglo XIX y el segundo tercio del siglo XX. El período estudiado nos permitirá evidenciar el paso de propietarios de raíz aristocrático colonial a otro de clase media limeña. Fenómeno que impactó en la marcha económica de esta hacienda, hasta su desaparición en la década de los 60 del siglo pasado.

Palabras Clave: hacienda, propietarios, aristocracia, clase media, marcha económica.

\begin{abstract}
The present research is interested in publicizing the historical details of the change of owners of the Maranga hacienda, between the beginnings of the republic in the nineteenth century and the second third of the twentieth century. The period studied will allow us to show the passage from owners of colonial aristocratic roots to another of Lima's middle class. Phenomenon that impacted on the economic progress of this hacienda, until its disappearance in the 60 s of the last centuries.
\end{abstract}

Keyword: hacienda, owners, aristocracy, middle class, economic march.

${ }^{1}$ Historiador peruano por la Universidad Nacional Mayor de San Marcos.

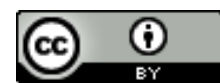




\section{INTRODUCCIÓN}

La hacienda Maranga, una importante propiedad agrícola de la costa central, es el objeto de estudio de esta investigación. La misma que es una continuación de nuestro trabajo Ejecutores de su depredación (2011), así como de una serie de artículos publicados en años anteriores sobre este tema. Por ello, este artículo pretende sumarse a esta área de investigación.

El estudio que ahora presentamos muestra en forma sumaria la correlación que existió entre el funcionamiento de la hacienda y el cambio de propietarios, durante el periodo comprendido entre 1821 y 1952. Etapa que se caracterizó por el tránsito de dueños de origen aristocrático a otro de clase media acomodada. La existencia de esta relación influyó muy marcadamente en la línea productiva de Maranga, la cual pasa de ser una unidad agrícola azucarera a algodonera y finalmente ganadera, hasta su desaparición como producto de la fiebre urbanizadora de la capital. A partir de estas dos premisas -el cambio de propietarios y la posesión de la hacienda- se testimoniará el curso de la dinámica económica, en la que estuvo inmerso este latifundio.

La revisión de la literatura historiográfica acerca de esta propiedad ha hecho posible recoger algunos aportes publicados hace pocos años (Ludeña 2004, Panizo 2008, Zavala 2010, Flores y otros 2015, Amorós 2017, Ávila 2018). Wiley Ludeña (2004), por ejemplo, en su registro de toda la producción de vivienda y urbanismo en Lima, cuantifica el proceso de urbanización de Maranga en diversas etapas desde 1960 a 1967. Antonio Panizo (2008) se refiere a la genealogía de la familia Panizo tanto en Europa como en el Perú. Por su parte José Zavala (2010) en su análisis de la evolución de la cadena láctea, nos habla puntualmente de la transformación de Maranga de una hacienda agrícola en ganadera.

Algunos otros aspectos han sido estudiados en coautoría por Daniel Flores, Marco Gamarra y Juan Florián (2015) quienes, en su trabajo sobre la construcción de la avenida Costanera en 1917, nos dan pormenores de los participantes en este negocio inmobiliario, en donde estuvieron involucrados miembros de la familia Escardó. Estos aportes son ampliados por Samuel Amorós (2017) y Soveyda Ávila (2018), el primero de ellos con una investigación sobre la capilla de la hacienda Maranga y la segunda con una secuenciación de las transformaciones que sufrió este predio a lo largo del tiempo. En ambos casos, los autores se centran en la propiedad de la hacienda por parte de los Panizo y los Escardó, así como las variaciones que sufre esta propiedad en su producción.

Este artículo se orienta en esta vía, profundizando y examinando algunos temas señalados por los citados investigadores. Dichos avances son analizados con el fin de elaborar una síntesis que explique cómo es que se produce el cambio de propietarios aristocráticos a los de clase media y, por ende, la actividad económica productiva de esta hacienda, de acuerdo con los intereses y las exigencias económicas de sus dueños. 
Para esta investigación se ha considerado documentos pertenecientes a escrituras de Protocolos Notariales, así como litigios judiciales que obran en la serie Tierras y haciendas ubicados en el Archivo General de la Nación (AGN). Complementariamente, se ha consultado también textos de la literatura historiográfica sobre el tema.

\section{DESARROLLO}

\section{Tendencias socioeconómicas a partir del cambio de propietarios de la hacienda Maranga}

La hacienda "Santa María" de Maranga, un latifundio cañero ubicado entre Lima y el puerto del Callao, atravesó a lo largo de su historia por épocas de bonanza y de crisis. Dichos procesos, sobre todo en tiempos difíciles para su funcionamiento, determinaron su cambio de propietarios (Palza 2011). Desde mediados del siglo XVIII hasta los primeros años republicanos del siglo XIX, esta empresa se mantuvo como heredad de la familia Panizo Foronda y sus descendientes, todos ellos pertenecientes a los grupos aristocráticos de la sociedad de aquel entonces.

Después de la independencia Flores (1998) menciona que, como consecuencia de ello, muchas propiedades agrícolas pasaron a manos de terceros, ya que sus propietarios en algunos casos fueron despojados de sus tierras y en otros, no fueron capaces de tenerlas debido principalmente a problemas económicos. Sin embargo, existió un sector de propietarios aristocráticos que si mantuvo la posesión sobre sus fincas, como es el caso de la familia señalada. Este es un primer momento, en el que estas propiedades agrícolas constituyen la base de poder socioeconómico y político de estos grupos. Al respecto, teniendo en cuenta esta tendencia Rosales (2008) menciona que, hacia la década de 1930, las tierras agrícolas de Lima todavía estaban en manos de familias aristocráticas como Echenique, Goycochea, Riva Agüero, Aparicio y por supuesto los Panizo, entre otros

Un segundo momento ocurre después, durante el período de la república Aristocrática y el Oncenio de Leguía. En esta etapa, al promediar la segunda década del siglo XX, Maranga pasa a manos de los Escardó, familia descendiente de inmigrantes italianos pertenecientes a sectores mesocráticos o de clase media, quienes toman la posesión y la administración de la hacienda hasta su desaparición a fines de los años 60 del siglo pasado. El mismo autor antes citado expresa, que lo mismo ocurrió con otras familias italianas que adquirieron otras haciendas, como Castaneto y Nosiglia (Aguilar, Concha y Taboada), Figari (Balconcillo), Gallese (San Miguel), Nicolini (Aliaga), Raineri de Traveri (Naranjal), Brescia (Limatambo Sur), Valle (Barboza), y otros (Rosales 2008, 123).

De esta manera, la transformación de Maranga como una unidad agrícola, luego agroindustrial y finalmente agropecuaria, ha estado muy ligada a su historia y al cambio de propietarios (Amorós 2017). Todo este proceso concluye con la extinción de la hacienda, generado por la expansión urbana de la ciudad de Lima. Por lo que ésta al igual que muchas propiedades rurales entre haciendas, fundos, chacras, establos $\mathrm{y}$ huertas fueron 
desapareciendo debido al avance del cemento y la "modernidad" (Orrego 2008). Negocio que le permitió a muchas familias dueñas de estas heredades, obtener cuantiosas ganancias económicas.

Drassinower (1980) manifiesta que, con la desaparición y la urbanización de las haciendas, sus expropietarios mudaron sus actividades económicas hacia la conformación de una élite industrializante. Grupo social que surge originalmente de la agricultura y la actividad mercantil.

En el tema que nos ocupa, desconocemos cuál fue el nuevo giro económico que los exdueños de Maranga desarrollaron luego de su desaparición. Pero, dado que es escasa la información al respecto, como hipótesis presumimos que posiblemente se orientó a la industria o las finanzas. Aspecto que por ahora deja abierta la posibilidad de una investigación posterior.

\section{Los propietarios aristocráticos de la hacienda Maranga, 1821-1920}

Como se ha señalado, parte de la nobleza limeña comienza a extinguirse después de la guerra de independencia, de suerte que una parte de ella optó por irse a España y los que se arriesgaron en quedarse se empobrecieron, dejando paso a una nueva generación de hacendados, como los Elguera, Laos, Montero, Elías, Aparicio, etc.; quienes no tuvieron vinculación con la nobleza, pero demostraron una mayor adaptabilidad a los cambios económicos y políticos que sucedieron en el Perú a partir de 1830 (Reyes 1995, 133).

No obstante, si bien la mayoría de estos nobles y sus descendientes no lograron mantener la posesión sobre sus dominios en la etapa independiente, algunos integrantes de esta aristocracia colonial mantuvieron la propiedad sobre parte de sus latifundios hasta bien entrado el siglo XIX, como es el caso de los Panizo Foronda (Reyes 1998, 508). De acuerdo con Reyes $(1995,122)$, los miembros de esta familia fueron poseedores de vastas propiedades e importantes cargos administrativos, judiciales y militares, quienes además mantuvieron una tradición terrateniente rentista que sustentó su poder social y económico. ${ }^{2}$

Durante el período anterior a la independencia, la hacienda Maranga le perteneció a Juan Ortiz de Foronda, un acaudalado terrateniente y comerciante que falleció soltero y sin hijos a la edad de 78 años, razón por la cual le heredó estas tierras a su sobrino Tomás Panizo y Foronda en 1811.3 Este personaje que también se desempeñó como tesorero de la universidad de San Marcos, contrajo matrimonio con Rosa Ramírez de Laredo Argudo, de cuya unión nacieron seis hijos: Manuel, muerto a los 26 años; Francisco Manuel, secretario del plenipotenciario peruano ante el gobierno de Chile; José, coronel del ejército; María Rosa, fallecida, primera esposa del marqués de Casares; Isabel, segunda esposa del citado marqués y Tomasa (Panizo 2008, 29).4

2 El último punto de vista también es ratificado por Palza (2021, 60).

3 AGN. Escribano Ignacio Ayllón Salazar, Prot. 45, 1827, fol. 1200-1200v.

4 AGN. Escribano Ignacio Ayllón Salazar, Prot. 45, 1827, fol. 1198v-1199v 


\section{Cuadro 1}

Propietarios de la hacienda Maranga (1811-1894)

\begin{tabular}{lc}
\hline Año & Propietario \\
\hline $\mathbf{1 8 1 1}$ & Tomás Panizo Foronda \\
\hline $\mathbf{1 8 2 9}$ & Rosa Ramírez Vda. de Panizo \\
\hline $\mathbf{1 8 3 9}$ & José Panizo y Ramírez \\
\hline $\mathbf{1 8 7 0}$ & Federico Panizo y Gonzáles \\
\hline $\mathbf{1 8 8 0}$ & Antonio Romagli y Steffano Berisso* \\
\hline $\mathbf{1 8 8 7}$ & Giovanni Rocca* \\
\hline $\mathbf{1 8 9 4}$ & Carlos y Federico Panizo Orbegoso \\
\hline \multicolumn{2}{c}{ Fuente: AGN. Protocolos Notariales, 1827; Ávila, 2018. } \\
\end{tabular}

Tomás Panizo dejó de existir en 1829 y desde entonces hasta 1838, fue su viuda quien se hizo cargo de la hacienda. A su regreso de Potosí en 1839, su hijo José Panizo Ramírez tomó en sus manos la dirección de Maranga y la de otros bienes familiares, en calidad de albacea de su padre Tomás Panizo.5 Durante esta etapa, en 1840, este trapiche y fundo azucarero acusaba serios problemas productivos, por lo que ya no reportaba ganancias a sus propietarios (Ávila 2018, 10).

A mediados del siglo XIX, como producto de la abolición de la esclavitud en 1854, decretada en el gobierno de Ramón Castilla, José Panizo liberó a sus esclavos (Ávila 2018, 10-11). Consecuentemente la mano de obra de la hacienda fue reemplazada durante la década de 1860, por labriegos coolies procedentes de China, quienes por las condiciones miserables en que laboraban, se sublevaron en 1871. A pesar de esta rebelión, la propiedad y sus dueños sobrevivieron (Amorós 2017, 6-7).

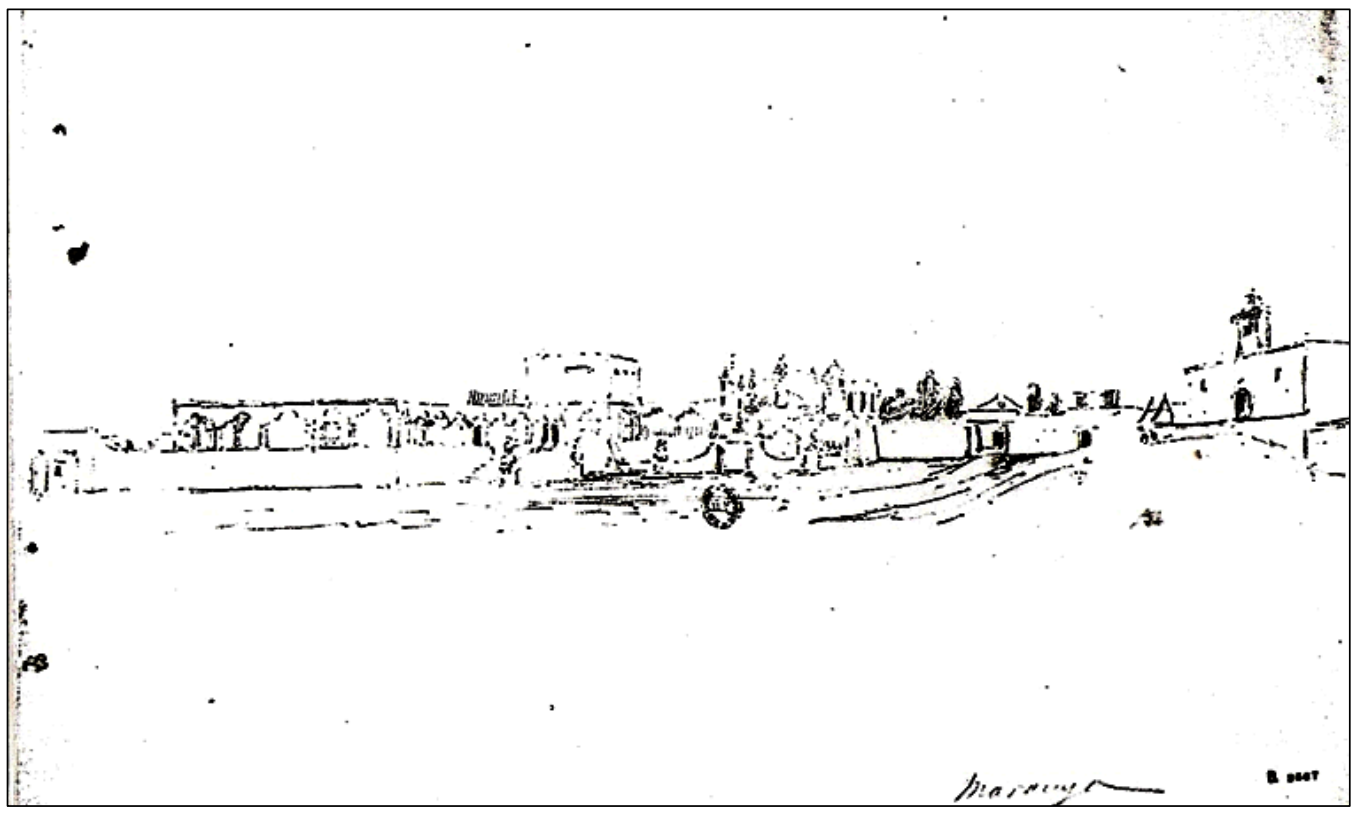

Figura 1. Dibujo de la hacienda Maranga el 12 de agosto de 1838, hecha por Leonce Angrand.

Fuente: Angrand, 1972.

5 AGN. Tierras y Hdas., L-33, c. 229, 1819, fol. 70. 
ISSN: 2710-0499 ISSN-L: 2710-0480

Salinas (2011, 21) refiere que el coronel José Panizo Ramírez de Laredo, Oficial de la Legión de Honor, contrajo nupcias con Ignacia González Pando y nació Federico Panizo Gonzáles (1846-1894). Este último sería el nuevo heredero de la hacienda Maranga en 1870. Ávila $(2018,11)$ resalta que su más arduo trabajo fue recuperar las tierras que fueron repartidas en herencia por su abuelo Tomás Panizo Foronda, para dejarlas a sus hijos como dueños absolutos de esta propiedad agrícola. Para ello, el 13 de mayo de 1872 celebró con su sobrina Virginia Peralta de Duthurburu un contrato de compraventa, mediante el cual ella cedió los derechos y acciones hereditarias que poseía en las testamentarias de sus bisabuelos en favor de su tío. ${ }^{6}$ De esta manera, a través de la compra de las acciones hereditarias de los coherederos respectivos, Panizo recuperó el control sobre las haciendas Maranga, Chillón y Santa Inés.7

En 1874 Federico Panizo se casó con la trujillana Manuela de Orbegoso Riglos, nieta del expresidente Luis José de Orbegoso (Cáceres 1923, 177). Matrimonio del que nacieron diez hijos: Isabel, Federico, María Amelia, María del Rosario, Luisa Dolores, José, Rosa, Manuela, Carlos y Filomena (Ludowieg 2000). Durante la dictadura de Nicolás de Piérola, Federico Panizo Gonzáles fue nombrado ministro de Justicia, Instrucción, Culto y Beneficencia el 14 de diciembre de 1879, cargo que ejerció aproximadamente hasta 1881. Asimismo, fue miembro de la junta directiva del Partido Demócrata fundado en julio de 1884 (Basadre 1984, 140).

El contexto de la guerra con Chile lo obligó a arrendar su hacienda a los italianos Antonio Romagli y Steffano Berisso, quienes introdujeron en la finca el cultivo de la uva. Al finalizar el conflicto bélico, Panizo arrendó nuevamente las tierras de Maranga en 1887, esta vez a Giovanni Rocca. Para 1894, Panizo deja como herederos de esta empresa agrícola a sus hijos Federico y Carlos Panizo Orbegoso, los que a partir de esa fecha quedaron al cuidado de la conducción de ella (Ávila 2018, 11).

Federico Panizo Orbegoso (1877-1926), estudió en la universidad de San Marcos, de la que se graduó como abogado en 1901. En 1913, fue nombrado juez de primera instancia de Lima, Huarochirí y Canta. En 1919 en el gobierno de José Pardo y Barreda, ocupó por breve tiempo la cartera de Justicia e Instrucción, interrumpida por el golpe de Estado de Augusto B. Leguía (Cáceres 1923, 177). Posteriormente, en 1924, fue nombrado presidente de la Corte Superior de Lima (Panizo 2008, 29). De su hermano Carlos no tenemos muchas referencias, solo se conoce que se casó con María García, de cuya unión nació Vicente Panizo García, muerto en acción en la batalla de Miraflores el 15 de enero de 1881, durante la invasión chilena de Lima. (Gardini S/f.).

Como se ha dicho, ambos hermanos tuvieron en sus manos el funcionamiento de la hacienda Maranga, hasta más o menos la década de 1920. Con ellos concluye esta etapa aristocrática de la hacienda, que duró aproximadamente una centuria. Lo que viene después es un proceso distinto, en el que el cambio de propietarios determinará seriamente el destino de Maranga.

${ }^{6}$ AGN. Escribano Claudio José Suárez, Prot. 898, 1872, fol. 192V-193.

7 AGN. Escribano Claudio José Suárez, Prot. 900, 1874, fol. 115v-116. 


\section{La emergencia de los propietarios mesocráticos de Maranga, 1920-1952}

Los hermanos Panizo Orbegoso, al entrar el nuevo siglo, en 1910, se asociaron con Rafael Escardó Salazar (1886-1952) y conformaron la "Sociedad Maranga Limitada", persona jurídica dedicada a la industria agropecuaria y la producción lechera (Amorós 2017, 7; Ávila 2018, 11). Esta sociedad se dedicó principalmente a la venta de leche, aunque también diversificó su producción al cultivo de algodón, empleando como operarios a emigrantes japoneses procedentes de Okinawa (Pinedo 2016).

Paralelamente, en 1917 Escardó también se convirtió en accionista de la compañía urbanizadora Miramar junto a su hermano Héctor (1879-1922), ingeniero de profesión y ministro de Fomento (1917-1918) y de Hacienda (1918-1919) durante el segundo gobierno de José Pardo (Samamé 1986, 316), quien estaba interesado en la inversión y urbanización de tierras cultivables (Ávila 2018, 11). En este sentido, el mismo año ambos participaron como socios en el proyecto de construcción de la avenida Costanera, iniciativa privada de la familia Boza, cuya empresa adoptó el nombre de Compañía urbanizadora de la avenida La Punta, la cual estuvo conformada por los dueños y/o administradores de las haciendas que atravesaba, en la que se encontraban Dolores Osma Vda. de Riva Agüero y Rosa Julia de Osma (dueñas del fundo San Cayetano) y los hermanos Héctor y Rafael Escardó (por la hacienda Maranga); mientras que Alberto Boza participó como gerente e ingeniero de la compañía. El objetivo de esta empresa era construir una avenida que uniera los balnearios de La Punta y San Miguel, urbanizando los terrenos aledaños. Empero, el proyecto quedó inconcluso debido a la crisis de 1929 y la consiguiente caída del régimen de Leguía (Flores et.al., 2015. 24).

En esta etapa de la historia de Maranga, los hermanos Panizo Orbegoso socios de Rafael Escardó, le entregaron a éste la gerencia de la empresa. La muerte de ambos hermanos, Carlos en 1924 y Federico en 1926, lo convirtió en propietario de toda la hacienda (Amorós 2017). Como tal, Rafael Escardó mantuvo en muy buena marcha el funcionamiento de la propiedad. Esto le permitió posicionar su empresa a través de la industrialización lechera, cuyo producto fue presentado como "Leche Maranga". Lo que la convirtió en la más grande empresa de lácteos en Lima, con un alto nivel de consumo en la población capitalina (Ávila 2018, 11).

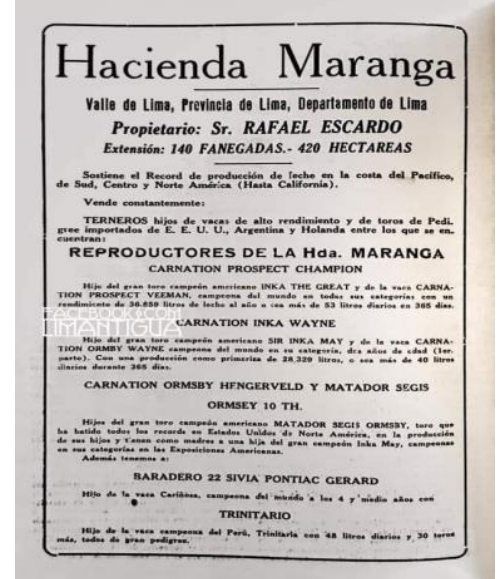

Figura 2. Anuncio publicitario de la hacienda Maranga.

Fuente: Facebook Lima Antigua 


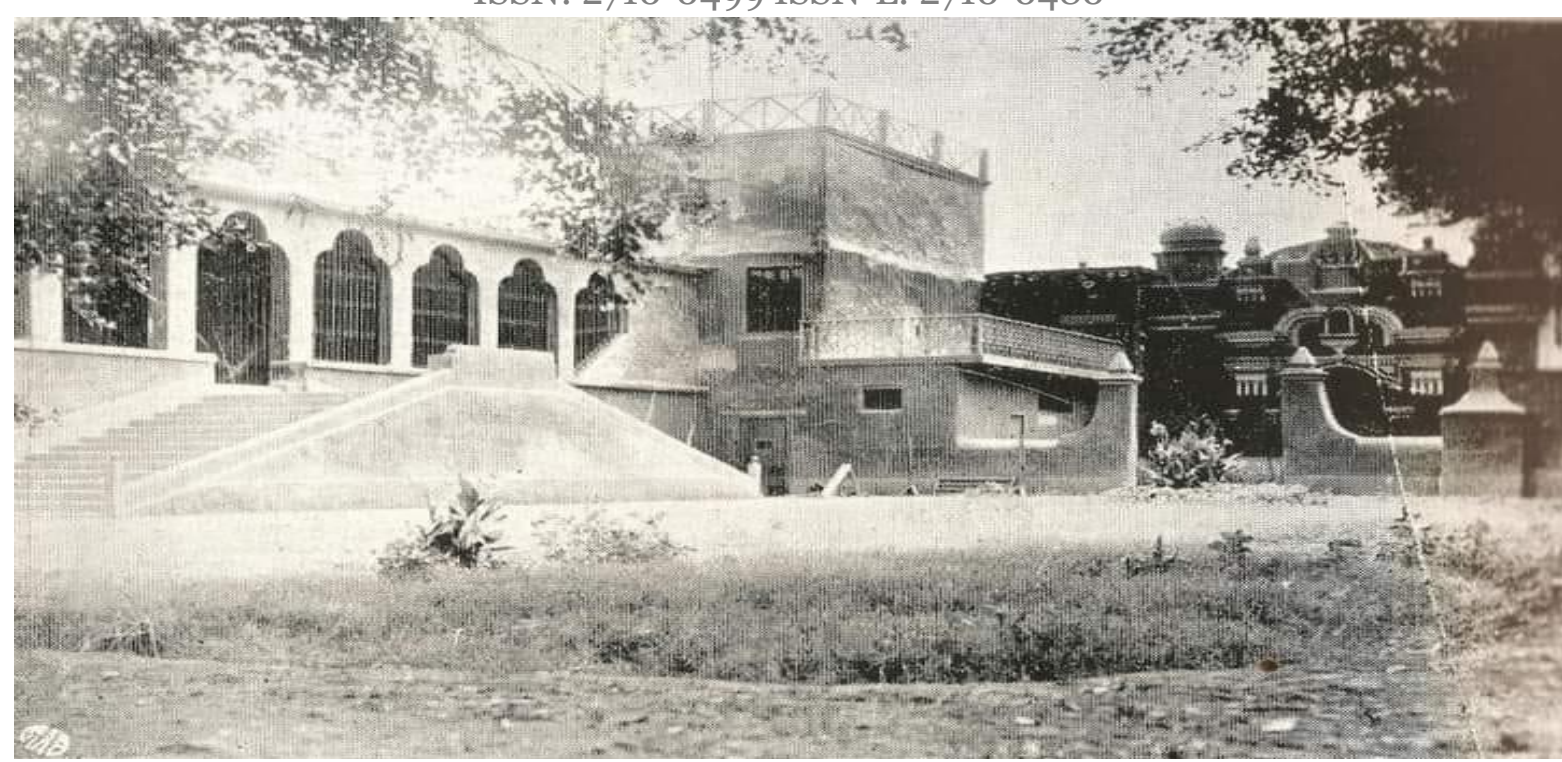

Figura 3. Casa hacienda de Maranga

Fuente: Fotografía de Alberto Santibáñez Salcedo, 1938.

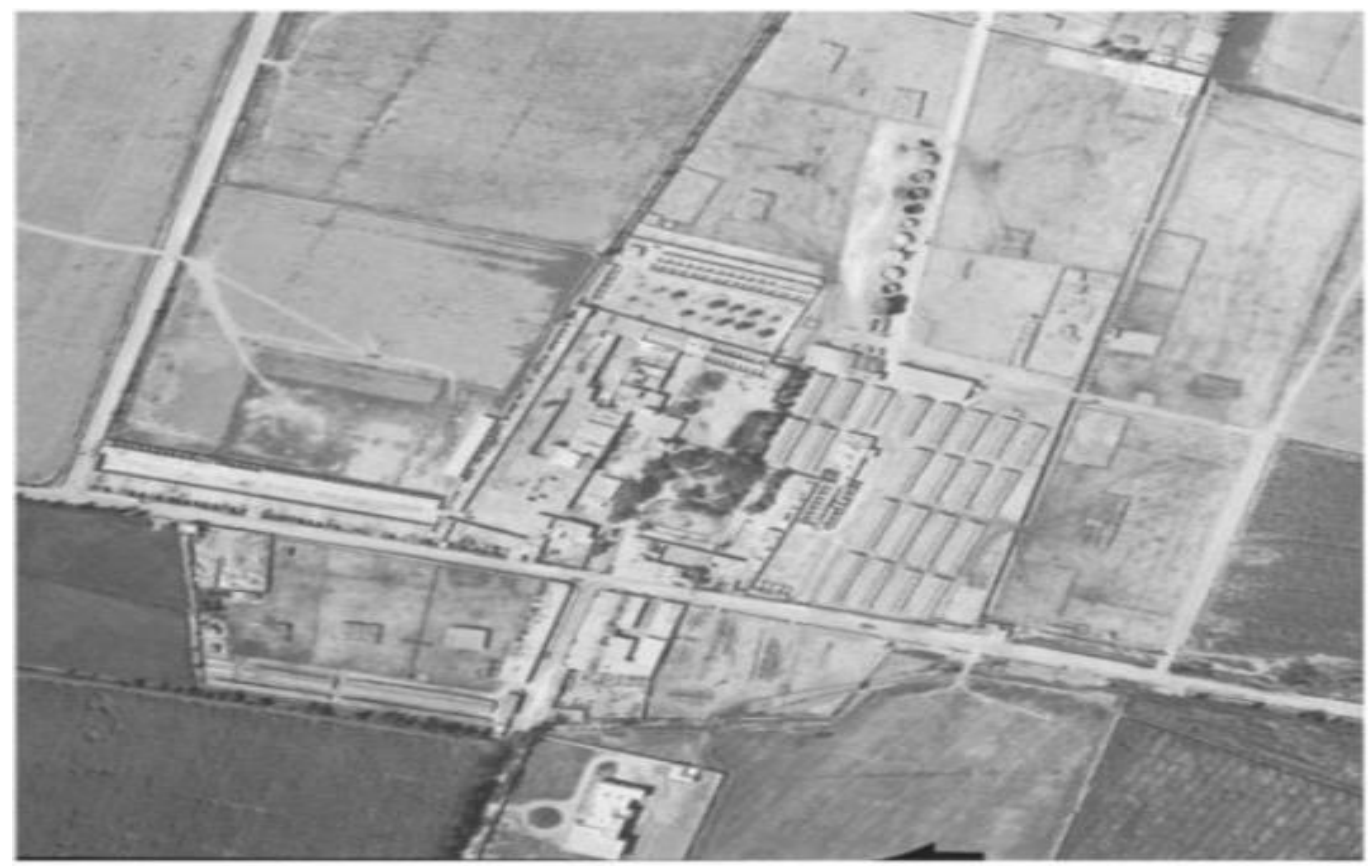

Figura 4. Fotografía aérea de la hacienda Maranga en 1944.

Fuente: Servicio Aerofotográfico Nacional.

A partir de entonces, la hacienda Maranga que tenía una extensión de 3’740,000 m² (374 Ha), funcionó con la razón social de Sociedad Agrícola Ganadera Maranga (Malpica 1981, 156). En 1952, Rafael Escardó falleció a la edad de 66 años, pasando la administración de la hacienda a manos de su hijo Rafael Escardó Aguirre (1917-1966) y su yerno Carlos Velarde Cabello (1909-2004). ${ }^{8}$ Estos últimos fueron quienes transformaron la Sociedad Agropecuaria Maranga en una Sociedad inmobiliaria, a partir de la lotización de las tierras de Maranguilla antes de la finalización de la década de los 50 (Ávila 2018, 12).

${ }^{8}$ Rafael Escardó hijo, quien llegó a ser alcalde distrital de San Miguel durante el período 1964-1966 (Pinedo 2016), murió a los 49 años, por lo que su cuñado Carlos Velarde quedó solo a cargo de Maranga.

Revista Revoluciones $\mathbf{- 4 8}$ - Vol. 4, No 7 (2022), pp. 41-52

Esta obra está bajo una licencia internacional Creative Commons Atribución 4.0. 


\section{Cuadro 2}

Propietarios de Maranga (1926-1952)

\begin{tabular}{cc}
\hline Año & Propietario \\
\hline 1926 & Rafael Escardó Salazar \\
\hline 1952 & $\begin{array}{c}\text { Rafael Escardó Aguirre y } \\
\text { Carlos Velarde Cabello }\end{array}$ \\
\end{tabular}

Fuente: Amorós 2017; Ávila 2018.

Como lo hace notar Zavala (2010, 13), esto se contextualiza en el desarrollo de un entusiasmo urbanizador que se inició en 1957, que afectó principalmente a las haciendas dedicadas al pan llevar y a la ganadería lechera como Lobatón, Balconcillo, Riso, San Juan, Limatambo, San Borja, Camacho, La Molina, Venegas, Venturo y obviamente Maranga. Corriente que continuaría en la década de los 60.

Situación que Aguirre (2016) asocia con el proceso de industrialización y las políticas urbanas entre 1900 y 1960, las cuales influyeron en la modificación del urbanismo de Lima. Ello motivó, como da cuenta Malpica (1981, 151), la oportunidad de un pingüe negocio que los grandes propietarios de tierras no desperdiciaron, lo que les permitió especular y amasar grandes fortunas con los terrenos ubicados en la periferia de la capital.

En el caso de la urbanización de las tierras de Maranga, ésta se vio favorecida por la construcción de la avenida La Marina, durante el segundo gobierno de Manuel Prado Ugarteche (Ávila 2018, 12). Asimismo, la política de vivienda desarrollada por los gobiernos de José Luis Bustamante y Rivero y de Fernando Belaúnde Terry contribuyeron también en este propósito. Situación que los últimos propietarios de la hacienda Maranga aprovecharon para incursionar de lleno en el negocio inmobiliario (Ávila 2018, 14).

\section{Cuadro 3}

Proceso de urbanización de Maranga

\begin{tabular}{lll}
\hline \multicolumn{1}{c}{ Nombre } & \multicolumn{1}{c}{ Promotor } & Año \\
\hline Urb.Maranga I-II Etapa & Urbanizadora Maranga S.A. & 1959 \\
Urb.Maranga IV-V Etapa & Urbanizadora Maranga S.A. & 1960 \\
\hline Urb.Maranga I-II-III-IV-V Etapa & Urbanizadora Maranga S.A. & 1960 \\
Urb.Maranga II Etapa & Urbanizadora Maranga S.A. & 1962 \\
Urb.Maranga III Etapa & Urbanizadora Maranga S.A. & 1962 \\
Urb.Maranga IV Etapa & Urbanizadora Maranga S.A. & 1963 \\
Urb.Maranga V Etapa & Urbanizadora Maranga S.A. & 1966 \\
Urb.Maranga III-V Etapa & Urbanizadora Maranga S.A. & 1967
\end{tabular}

Fuente: Ludeña, 2004. 
ISSN: 2710-0499 ISSN-L: 2710-0480

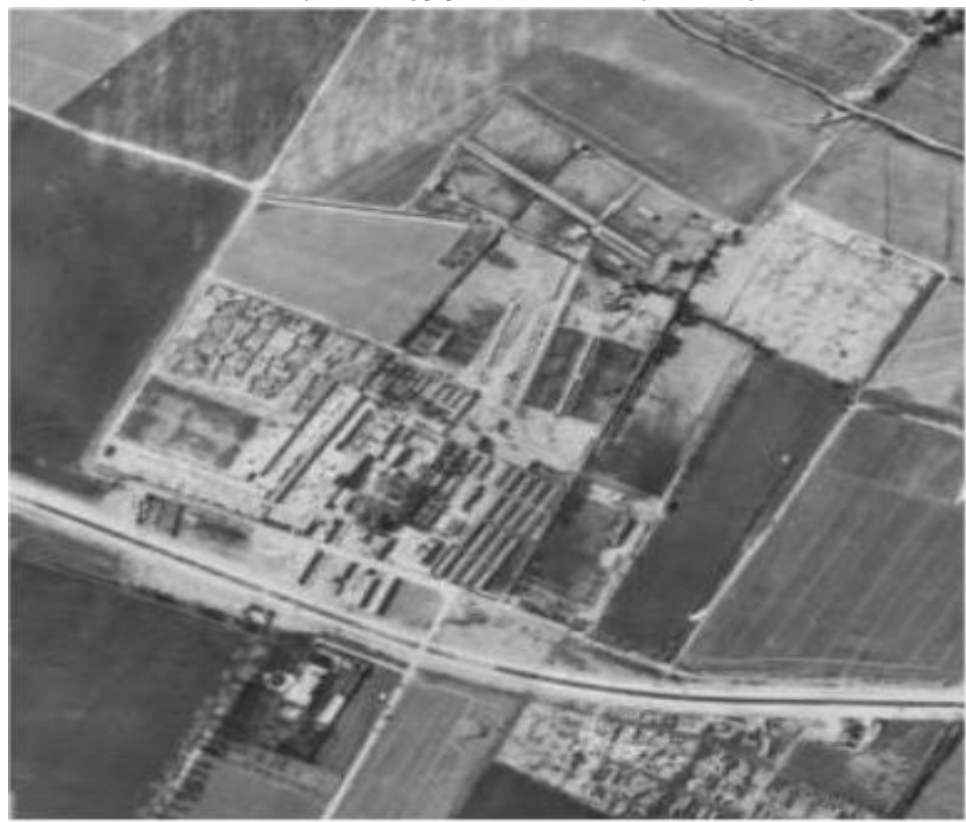

Figura 5. Fotografía aérea de la hacienda Maranga en 1960 Fuente: Servicio Aerofotográfico Nacional.

El proceso de urbanización de las tierras de Maranga se concretizó antes de la dación de la Ley de Reforma Agraria de 1969, dictada durante el mandato del general Juan Velasco Alvarado, por lo que los propietarios de esta empresa agrícola no se vieron afectados por las disposiciones de esta reforma. Con la desaparición de la hacienda se perdió también la casa hacienda, la cual fue destruida en su totalidad, pues sus dueños no tuvieron el tino suficiente de conservarla como patrimonio histórico (Ávila 2018, 15). Lo único que aún queda en pie hasta la actualidad es la capilla, que se encontraba anexa a ella, la misma que hasta el año 1976 se encontraba en abandono y que gracias a restauraciones efectuadas en 1984 y el 2017 ha permitido la conservación y su puesta en valor. La cual permanece allí como testigo silente del pasado de Maranga y de los que en su oportunidad la manejaron.

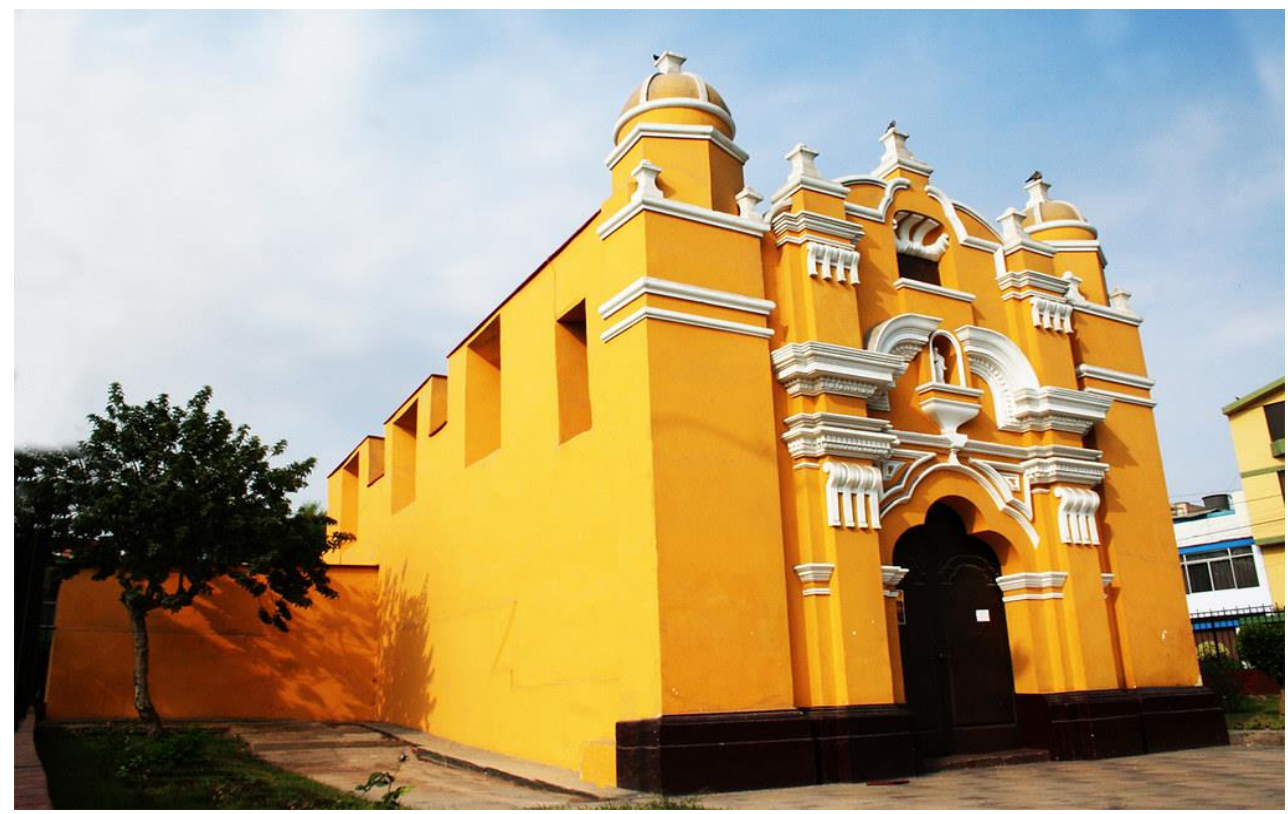

Figura 6. Capilla de la hacienda Maranga, ubicada en el parque Paul Harris, distrito de San Miguel

Revista Revoluciones $\mathbf{- 5 0 -}$ Vol. 4, $\mathrm{N}^{\circ} 7$ (2022), pp. 41-52

Esta obra está bajo una licencia internacional Creative Commons Atribución 4.0.

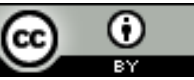




\section{CONCLUSIONES}

Las conclusiones de este estudio dejan en claro que la dinámica de la marcha económica de la hacienda Maranga, estuvo ligada a sus propietarios y al cambio de ellos. Como lo hemos sugerido, esta relación implicó pasar de los dueños aristocráticos pertenecientes a la oligarquía a los de origen mesocrático o de clase media alta. Transferencia que se ejecutó a través del establecimiento de sociedades comerciales que se establecieron entre ambos sectores, durante las primeras décadas del siglo XX.

El análisis de esta estrategia también nos muestra la vinculación que existió entre los propietarios de esta hacienda con el poder económico y político, situación que se evidencia con mayor claridad en la familia Panizo y de igual modo -aunque en menor medida-, en la familia Escardó. Las estrategias descritas por medio de estas interacciones contribuyeron a definir el rol que tenían estos actores dentro de la sociedad, al orientar la producción de la hacienda hacia los requerimientos del mercado (azúcar, algodón y lácteos).

En este devenir, los cambios urbanos que sufre Lima en el siglo XX, por la influencia de la industrialización textil y las políticas urbanísticas, determinaron la suerte de Maranga como empresa agrícola ganadera, la cual llega a su fin cuando sus últimos propietarios decidieron urbanizarla. Tendencia que les permitió acumular capitales para diversificarlos hacia otras actividades económicas.

\section{REFERENCIAS BIBLIOGRÁFICAS}

Aguirre, M. (2016), Los cambios urbanísticos de Lima entre los años 1900-196o por la influencia de la industrialización y las políticas urbanas. Foz do Iguaçu: Universidade Federal de Integração Latino-Americana.

Angrand, L. (1972), Imagen del Perú en el siglo XIX, Lima: Edit. Milla Batres.

Amorós, S. (2017), La capilla de la hacienda Santa María de Maranga de Lima. Lima: Instituto de Investigación del Patrimonio Cultural-Universidad Ricardo Palma.

Ávila, E. (2018), Continuidad y cambio en los terrenos de la antigua hacienda Santa María de Maranga. Lima: Universidad Nacional de Ingeniería.

Basadre, J. (1984), Perú: problema y posibilidad. Lima: COTECSA.

Cáceres, E. (1923), España en el Perú. Lima.

Drassinower, S. (1980), Testimonio de una experiencia industrial peruana, T. I (1954-1973). Lima: Edit. Minerva.

Flores, D. (2015), La ciudad y el mar: la avenida Costanera entre la Lima Aristocrática y la Lima del Oncenio (1917-1930). Lima: PUCP, 2015.

Gardini, P. R. (S/f), Mis abuelos, mis bisabuelos y mis tíos y tías. Lima. En: talia.pe.tripod.com/elsitioderosaelenagardinipanizo/id11.htm/ [Accesado el 2-set2021]

Ludeña, W. (2004), Lima: historia y urbanismo, 1821-1970, Vol. I. Lima: Universidad Nacional de Ingeniería. 
Ludowieg, M. (2000), “Genealogía de la Familia Díez de Rávago”, en Revista del Instituto Peruano de Investigaciones Genealógicas, No. 23, Lima, pp. 139-210.

Malpica, C. (1981), Los dueños del Perú. Lima: PEISA, 12ava edic.

Orrego, J. L. (2008), Haciendas de Lima. Lima, 3-jun-2008. En: blog.pucp.edu.pe/blog/juanluisorrego/2008/o6/o3/haciendas-en-lima.

Palza-Becerra, H. (2011), Ejecutores de su depredación. El cálculo económico en las empresas feudal coloniales: la hacienda "Santa María" de Maranga. Siglo XVIII-XIX. Lima: Grupo Gráfico del Piero.

Palza-Becerra, H. (2021), "Tiempos de libertad. El duro aprendizaje republicano del Perú Independiente", en Revista Revoluciones, No. 5, pp. 54-72.

Panizo de Pablo, A. (2008), Los hucpoldingios son carolingios ¿Confirmado genéticamente? Historia del noble apellido Panizo. Madrid: Edit. Veritatem Inquiro.

Pinedo, H. (2016), Historia del distrito de San Miguel. Lima, 16-may-2016. En: humbertopinedomendoza.blogspot.com/2016/05/historia-del-distrito-de-san-miguelde-16.html?m=1

Reyes, A. (1995), “La nobleza limeña: fracción hegemónica, 1750-1820”, en Ciencias Sociales, No. 1, UNMSM, pp. 119-134.

Reyes, A. (1998), "La familia Montero. Empresarios nacionales, siglo XIX", en Actas del I Encuentro Internacional de Peruanistas. Estado de los estudios histórico-sociales sobre el Perú del siglo XX, T. I, Universidad de Lima, pp. 501-532.

Rosales, R. (2008). Para ver más allá de lo evidente: Etnohistoria urbana, cultura y poder en el sector marginal-urbano San Juan Masías, San Borja, Lima:1972-20o6, Tesis de pregrado en Antropología. Lima: UNMSM.

Samamé, M. (1986), "Escardó, Héctor F.”, en Carlos Milla Batres (ed.), Diccionario Histórico y Biográfico del Perú. Siglos $X V-X X$. Lima: Edit. Milla Batres.

Salinas, A. (2011), Las damas del guano. Género y modernidad en Lima, 1850-1879. Lima: Fondo Editorial UNMSM, 2011.

Zavala, J. (2010), Cien años de lechería en el Perú. Lima: Ministerio de Agricultura. 